\title{
Erratum to: Biomechanical comparison of graft structures in anterior cruciate ligament reconstruction
}

\author{
Breck R. Lord ${ }^{1,2} \cdot$ Hadi El-Daou $^{1} \cdot$ Bhushan M. Sabnis $^{2} \cdot$ Chinmay M. Gupte $^{3}$. \\ Adrian J. Wilson ${ }^{2} \cdot$ Andrew A. Amis ${ }^{1,3}$
}

Published online: 18 October 2016

(C) European Society of Sports Traumatology, Knee Surgery, Arthroscopy (ESSKA) 2016

\section{Erratum to: Knee Surg Sports Traumatol Arthrosc}

DOI 10.1007/s00167-016-4316-6

In the original article, one of the co-author's (Adrian M. Wilson) middle initial has been published incorrectly. The correct name should be Adrian J. Wilson.

The online version of the original article can be found under doi:10.1007/s00167-016-4316-6.

\section{Andrew A. Amis}

a.amis@imperial.ac.uk

1 The Biomechanics Group, Department of Mechanical Engineering, Imperial College London, London SW7 2AZ, UK

2 Basingstoke and North Hampshire Hospital, Basingstoke, UK

3 Musculoskeletal Surgery Group, Department of Surgery and Cancer, Imperial College London School of Medicine, Charing Cross Hospital, London, UK 